\title{
Histologic and Histomorphometric Analysis of Bone Regeneration with Bovine Grafting Material after 24 Months of Healing. A Case Report
}

\author{
Renzo Guarnieri ${ }^{1, *(\mathbb{D})}$, Fabrizio Belleggia ${ }^{2}$, Patricia DeVillier ${ }^{3}$ and Luca Testarelli ${ }^{1}$ \\ 1 Department of Dental and Maxillofacial Sciences, School of Dentistry, University La Sapienza, \\ 00100 Rome, Italy; lucatestarelli@gmail.com \\ 2 Private Periodontal Implant Practice, 00100 Rome, Italy; fabriziobelleggia@gmail.com \\ 3 Department of Oral and Maxillofacial Pathology, University of Alabama at Birmingham, \\ Birmingham, AL 35294, USA; Patriciadevillier@gmail.com \\ * Correspondence: renzoguarnieri@gmail.com; Tel.: +39-342-5224458
}

Received: 28 May 2018; Accepted: 31 July 2018; Published: 8 August 2018

\begin{abstract}
Anorganic bovine bone mineral matrix (ABBMM) has been reported to have osteoconductive properties and no inflammatory or adverse responses when used as grafting material in sinus augmentation procedures. However, controversy remains in regard to degradation rate of ABBMM. The aim of this study was to histologically and histomorphometrically evaluate the degradation of ABBMM in human bone samples obtained in one patient 24 months after sinus augmentation. Materials and Methods: The histologic and histomorphometric analysis was performed by means of light microscopy in three specimens harvested from the same patient, Results: After 24 months the tissue pattern appeared to be composed of residual particles, some in close contact with the newly formed bone, others separated by translucent areas and osteoid tissues. Newly-formed bone presented different levels of maturation and numerous osteocytes, with greater numbers in bone closer to the grafted particles $(27.3 \%$ vs. $11.2 \%, p<0.05)$. The histomorphometric analysis showed mean values of $40.84 \%$ newly-formed bone, $33.58 \%$ residual graft material, $23.84 \%$ marrow spaces, and $1.69 \%$ osteoid tissue, Conclusions: Even though ABBMM underwent considerable resorption, a great amount of residual grafting material was still present after two years of healing following sinus augmentation. This study confirms that the bovine grafts can be classified as long-term degradation materials.
\end{abstract}

Keywords: histology; histomorphometry; anorganic bovine bone mineral matrix; sinus augmentation

\section{Introduction}

The final goal of any bone grafting procedure should be the achievement of $100 \%$ living and reactive tissue able to undergo a sustained state of remodeling. Autogenous bone has always been considered the gold standard for grafting procedures because of the reproducible healing mechanism of osteogenesis, osteoinduction, and osteoconduction [1]. However, autogenous bone also has disadvantages, including limited amount of available graft material, an additional surgical site, donor site morbidity, and the requirement of general anesthesia for extraoral bone harvesting [2,3]. Moreover, when used in sinus augmentation, autogenous bone has been reported to be rapidly resorbed and this might compromise implant placement [4].

In order to overcome these disadvantages, xenogenic bone has been proven as alternative graft material in bone regeneration $[5,6]$.

Anorganic bovine bone mineral matrix (ABBMM) is by far the most commonly used and researched xenograft. Most of the available ABBMM consist of deproteinized and sterilized bovine 
bone. Such matrices provide a scaffold for cells migration and are involved in the osseointegration and remodeling processes [7].

Contrasting data are present in the literature regarding whether ABBMM is completely degradable and whether the presence of residual graft particles could interfere with the healing process of regenerated sites [8]. This discrepancy may be attributed to differences in the type of study (animal vs. human studies), surgical approach, biopsy technique, or histological evaluation method [9]. Non-resorption might result in shielding of the newly-formed bone from physiological stresses necessary for further remodeling and maturation. Moreover, it could also influence or interfere with the osseointegration process of dental implants and bone-to-implant contact [1,10]. Residual ABBMM granules around the dental implant body could represent a locus minoris resistentiae in case of peri-implant infection [11]. Few human histologic reports on ABBMM resorption rate over time are available in the literature [12-16]. Histological studies have shown that ABBMM presents a markedly faster resorption in the initial period (3/6 months) after graft insertion [11,17-19], but it is slowed down in subsequent time periods $[16,20]$. Contrasting results are reported in literature also on the biological interactions occurring at the bone-ABBMM interface [21]. Once the graft particles incorporation in the bone create a dense and hard tissue network they act similar to the host bone and provide appropriate biologic support [22-25]. On contrary, the presence of multinucleated cells and osteoclastic activity surrounding the residual particles suggests that the bone remodeling process may be negatively influenced [26-29].

It is quite important to understand the effect of residual graft particles at different time periods and if there is any interference with the natural bone processes that might possibly affect the prognosis in human.

For that reason, we investigated the biopsies taken from one patient after 24 months of maxillary sinus augmentation by using ABBMM. The aim of this study was to obtain histomorphometric measurements of newly-formed bone, marrow spaces, residual biomaterial particles and number of osteocytes being present.

\section{Materials and Methods}

A 50-year-old female with a monolateral maxillary edentulism involving the premolar/molar regions underwent a sinus augmentation procedure in January 2016. The preoperative mean height of the subantral bone was $<4 \mathrm{~mm}$. The patient was a non-smoker and had a non-contributory medical history. One-hundred percent of ABBMM was used in the surgical procedure. The patient, who was previously accepted in a study approved by the Ethical Committee of La Sapienza University, Roma; (reference no. 4597), provided written informed consent for all procedures. The study was conducted according to the principles embodied in the Helsinki Declaration for biomedical research involving human.

A thorough preoperative evaluation was performed, including the study of mounted diagnostic cast and diagnostic wax-up. Radiographic examination included both intraoral and computerized tomography. Preoperative medications included amoxicillin, and $1 \mathrm{~g}$ twice a day of clavulanic acid (NeoDuplamox, Procter and Gamble), starting one day prior to surgery and continuing until eight days post-surgery. Patient was asked to rinse with $0.2 \%$ chlorhexidine gluconate the day of surgery and twice a day for 14 days after the procedure.

Under local anesthesia, a crestal incision was made slightly toward the palatal aspect and throughout the entire length of the edentulous segment, supplemented by buccal releasing incisions mesially and distally. Full thickness flaps were elevated to expose the alveolar crest and the lateral wall of the maxillary sinus. A trap door was made in the lateral sinus wall using a round bur under sterile saline solution irrigation. The door was rotated inward and upward. The sinus membrane was elevated with curettes of different shapes until it became completely detached from the lateral and inferior wall of the sinus. The ABBMM (MinerOssX, BioHorizons, Birmingham, AL, USA) was mixed with venous blood and packed carefully in the sinus cavity. MinerOssX is a natural cancellous (spongiosa) and 
cortical bovine bone matrix with $250-1000 \mu \mathrm{m}$ particles distribution size. It is produced by a chemical removal of organic components, has $75-80 \%$ porosity and a crystal size of approximately $10 \mu \mathrm{m}$ [30].

The mucoperiosteal flap was then re-positioned and sutured with multiple horizontal mattress sutures. Sutures were removed two weeks after surgery. Postsurgical visits were scheduled at monthly intervals to check the course of healing. The sinus was allowed to heal for 24 months, and then three implants were placed into the grafted area.

\section{Histologic Analysis}

Twenty-four months after maxillary sinus augmentation, three bone cores were harvested, before implants placement, using a $3.5 \mathrm{~mm}$ diameter trephine under cold $\left(4-5{ }^{\circ} \mathrm{C}\right)$ sterile saline solution irrigation. The bone specimens were immediately fixed in $10 \%$ buffered formalin and embedded in a glycolmethacrylate resin. After polymerization, specimens were sectioned along their longitudinal axis to a thickness of 70 microns (plastic microtome, RM 2265, Leica, Buffalo Grove, IL, USA). Slides were stained with Trichrome and examined using an Olympus B51 microscope (Olympus America, Lake Success, NY, USA). The core area of every specimen was chosen for histomorphometric analysis. Images were captured with a Q-Imaging camera, (Retiga R1 ${ }^{\mathrm{TM}}$ CCD camera, 32-0013B-157, 12-bit color, Surrey, BC, Canada) and area fraction percentages of every component in was measured automatically using Bioquant ${ }^{\circledR}$ image analysis software (R\&M Biometrics, Nashville, TN, USA). To evaluate bone quality, histomorphometric measurements were recorded according to the nomenclature approved by the American Society of Bone and Mineral Research, and analyzed by a blinded researcher using Ky Plot 2.0 software (Informer Technologies, Inc., New York, NY, USA).

\section{Results}

Microscopic examination of processed bone core specimens showed newly-formed bone in close contact with ABBMM particles (Figure 1).

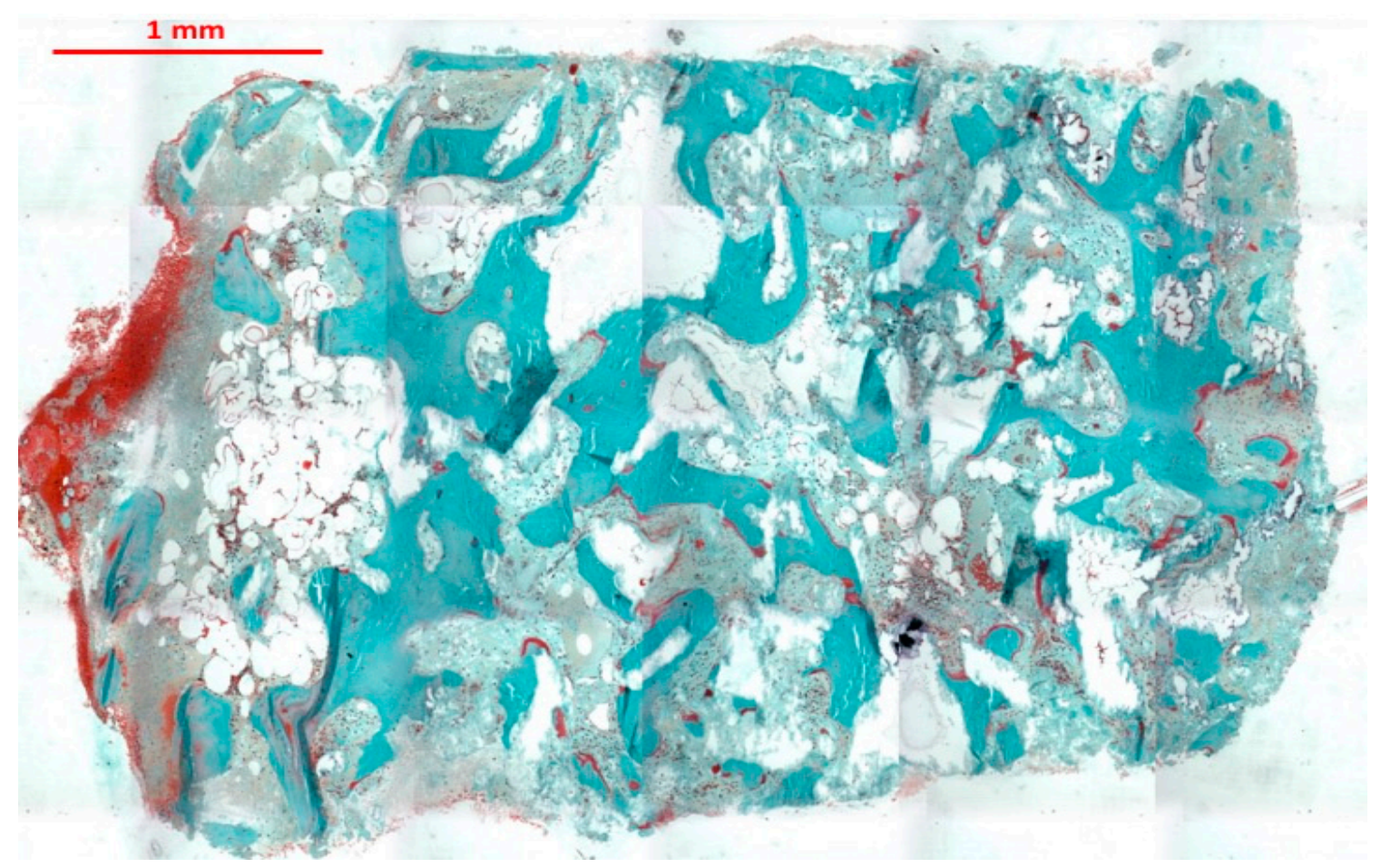

Figure 1. Panoramic histological image of bone core biopsy taken after 24 months from maxillary sinus augmentation (trichrome stain $\times 5$ ). Residual ABBMM particles surrounded by vital bone which presents different levels of maturation. 
Most of the graft particles were surrounded by newly-formed bone. In some areas, the graft particles were in contact with marrow spaces. The presence of non-mineralized matrix (osteoid seam) was also observed at the interface with the ABBMM (Figures 2 and 3).

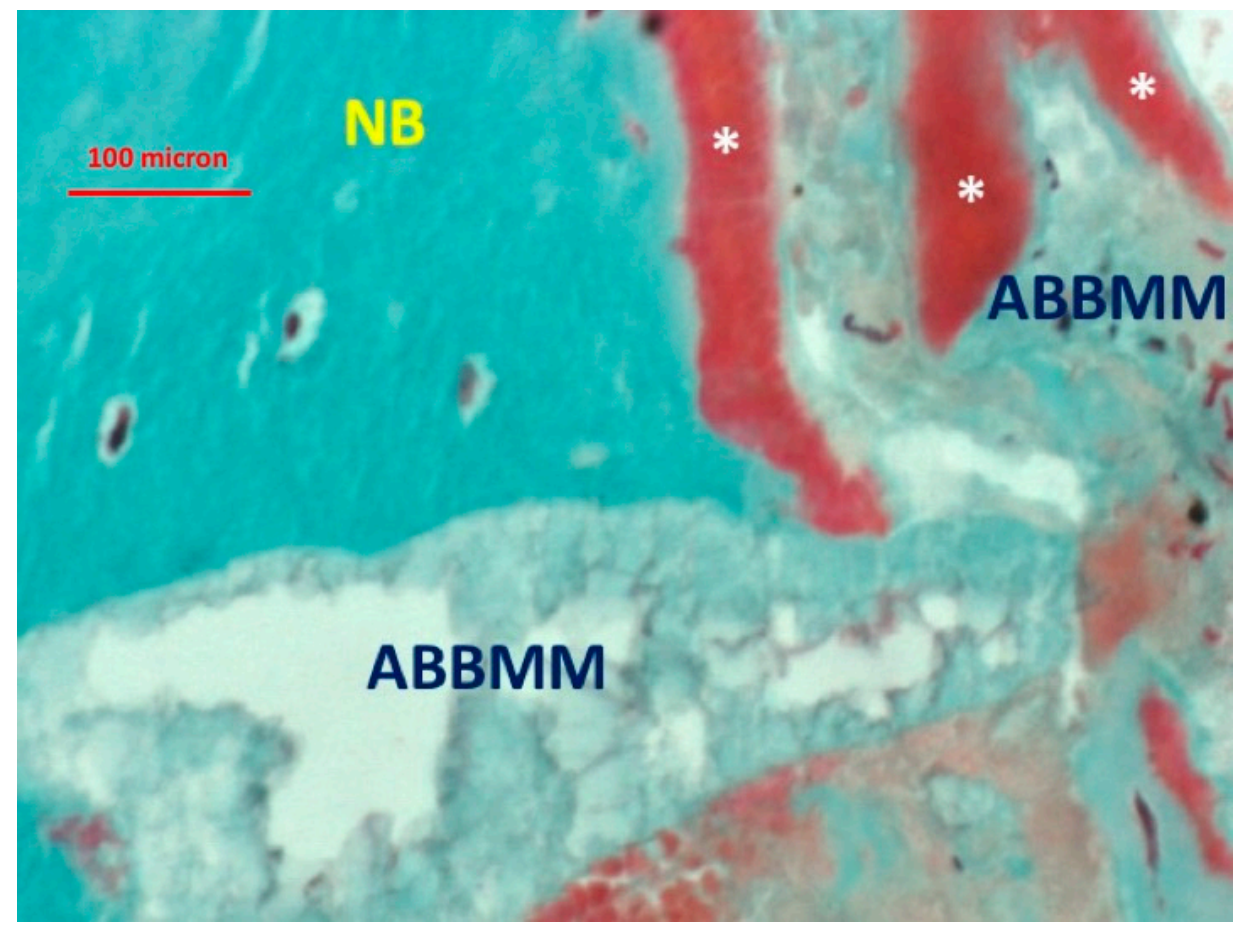

Figure 2. Presence of non-mineralized osteoid matrix $\left(^{*}\right)$ at the interface with the ABBMM (trichrome stain $\times 20)$.

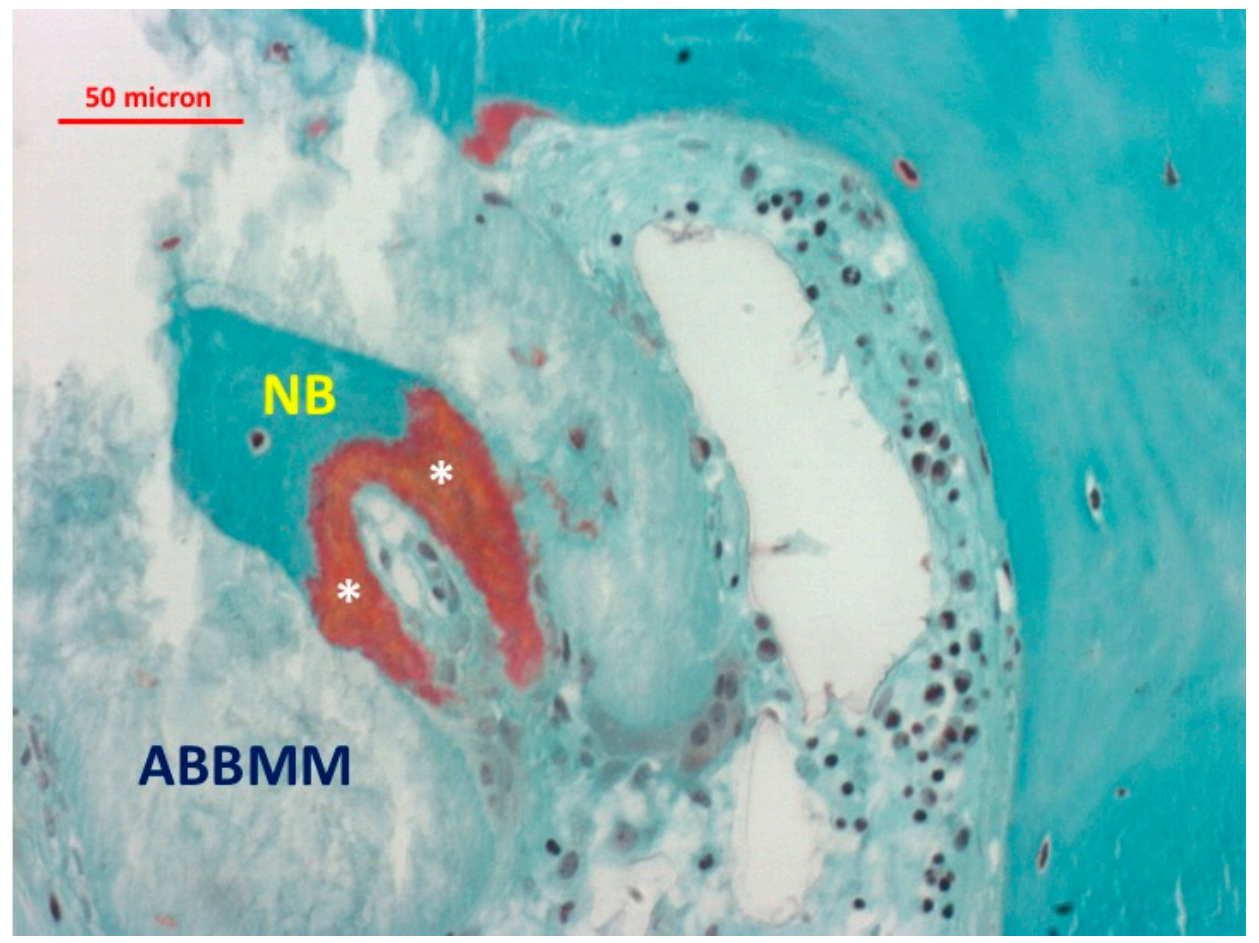

Figure 3. Presence of non-mineralized osteoid matrix $\left(^{*}\right)$ at the interface with the ABBMM (trichrome stain $\times 20)$. 
The newly-formed bone abutting the graft particles showed viable bone and lacunae with osteocytes. Little granulocytic infiltrate was present in the bone marrow spaces. At higher magnification, a few multi-nucleated cells at the interface between the biomaterial particles and new formed bone were detected (Figures 4-6). In addition, many translucent areas at the interface between the biomaterial particles and newly-formed bone and osteoid tissue were found (Figure 5). Histomorphometric data are reported in Table 1.

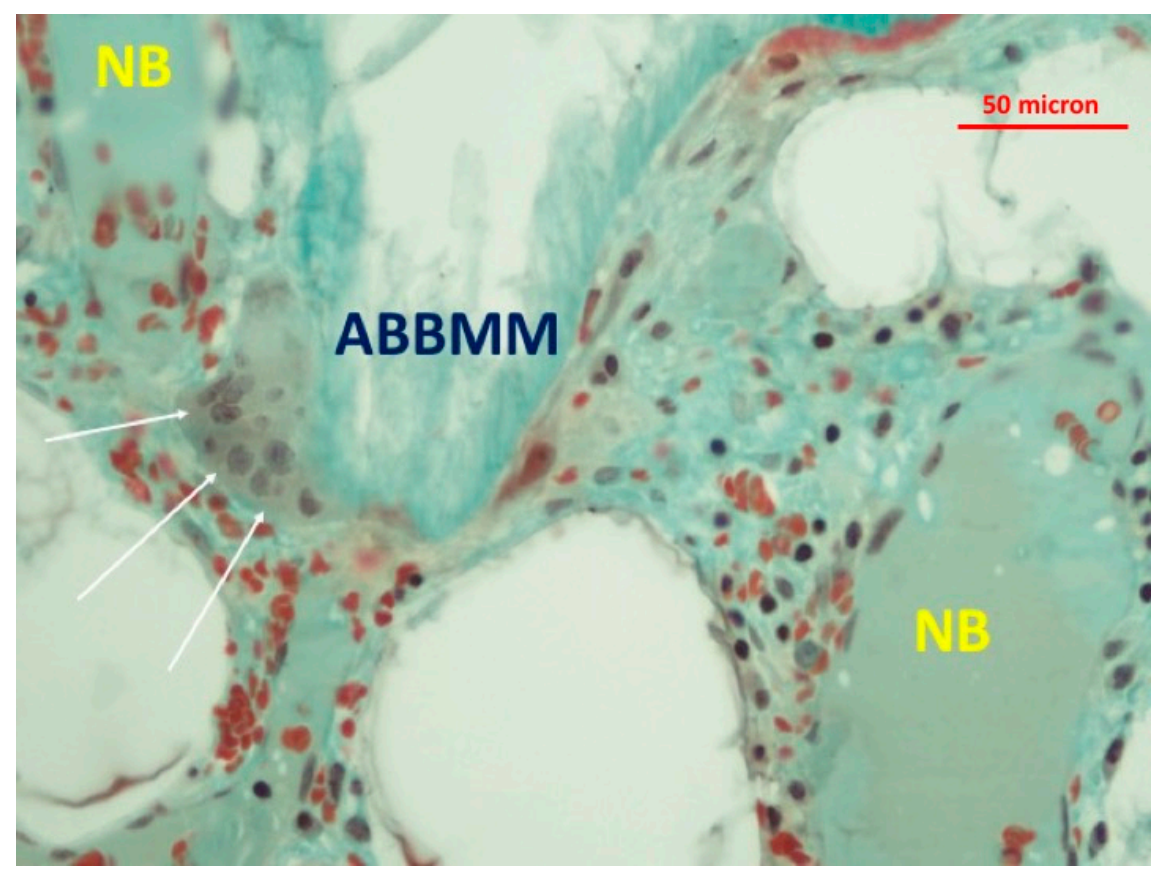

Figure 4. Presence of multi-nucleated cells (white arrows) at the interface between the biomaterial particles (ABBMM) and newly-formed bone (NB) (trichrome stain $\times 20)$.

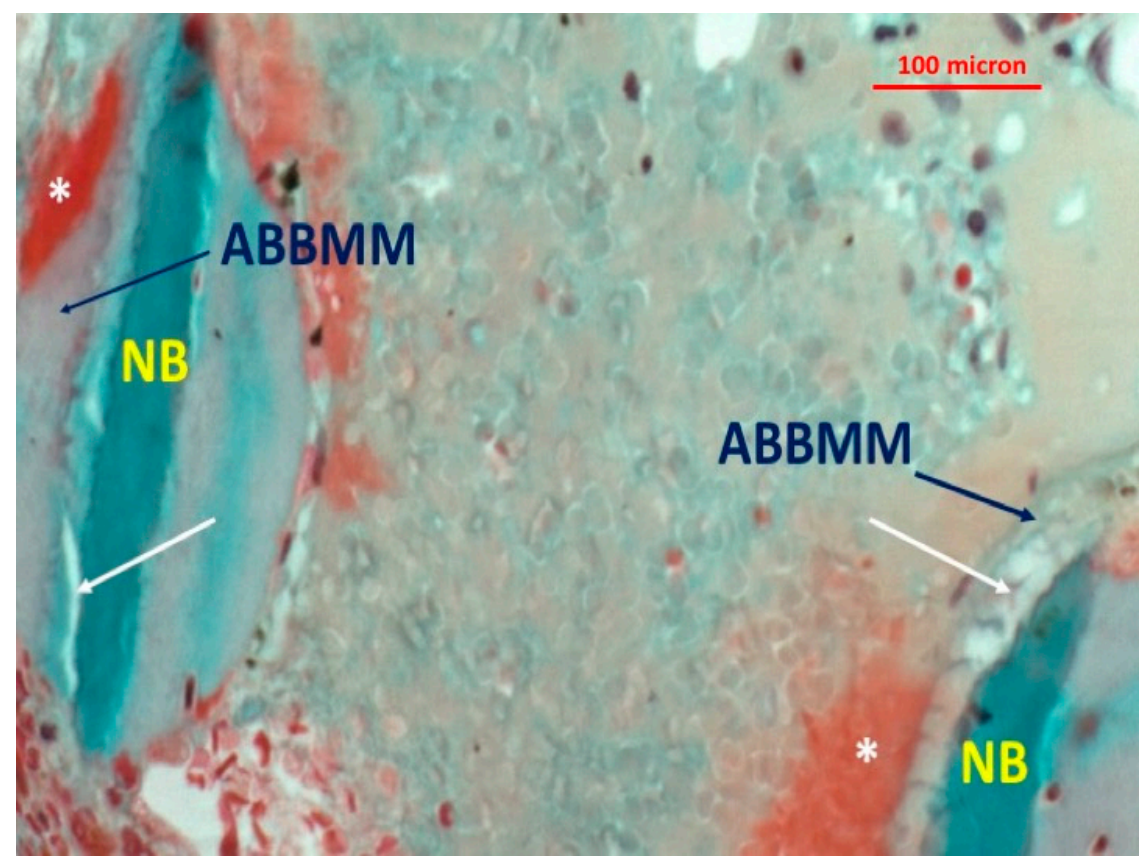

Figure 5. Presence of translucent areas (white arrows) at the interface between the biomaterial particles $\left(\right.$ ABBMM) and newly-formed bone. Non-mineralized osteoid matrix $\left({ }^{*}\right)$ (trichrome stain $\times 40$ ). 


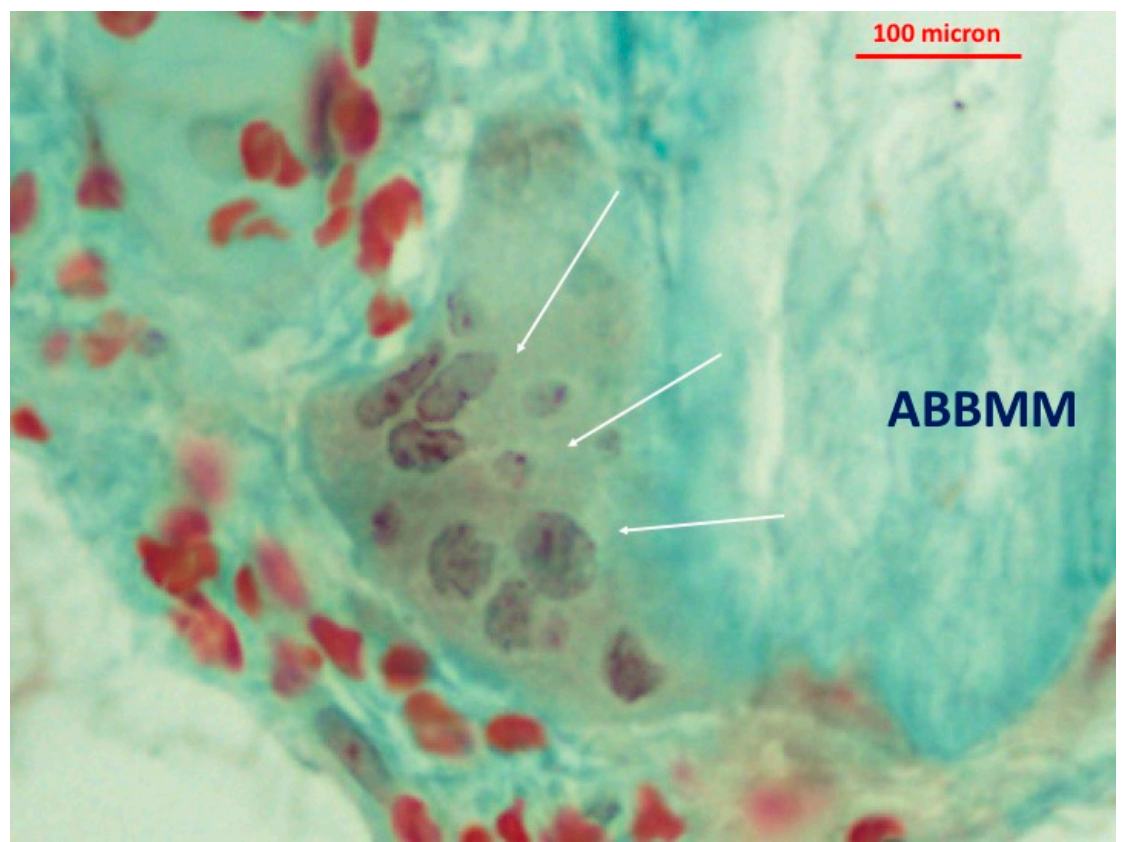

Figure 6. Higher magnification of Figure 4 showing multi-nucleated cells in close approximation and in contact with ABBMM surface.

Table 1. Histomorphometric data (mean \pm SD).

\begin{tabular}{ccc}
\hline Column & Mean & SD \\
\hline Tt. Tissue Area. & 7.205 & $(1.8)$ \\
Tt. Area of Bone & 1.952 & $(0.5)$ \\
Tt. Area of Bone Graft & 3.103 & $(0.9)$ \\
Tt. Osteoid Area & 0.095 & $(0.03)$ \\
Tt. Connective Tissue Area & 2.054 & $(0.8)$ \\
\%. Marrow spaces/Tt. Area & 23.84 & $(4.6)$ \\
\%. Bone/Tt. Tissue Area & 40.84 & $(3.3)$ \\
\%. Graft/Tt. Tissue Area & 33.59 & $(2.8)$ \\
\%. Osteoid/Tt. Tissue Area & 1.697 & $(0.4)$ \\
\hline
\end{tabular}

\section{Discussion}

It is important to understand the process of new bone formation and remodeling during early and late healing phases at sites grafted with ABBMM. The current study presents histomorphometric measurements of newly-formed bone, marrow spaces, residual biomaterial particles, and osteocytes in biopsies taken from one patient after two years of maxillary sinus augmentation by using ABBMM. It was observed that the amount of residual graft material was $33.58 \%$. The results also showed a mean value of $40.84 \%$ newly-formed bone which is accordance to the previously reported sinuses grafted with ABBMM [21].

On the other hand, bone sample harvested from one extraction socket regenerated with the same ABBMM showed a mean value of $26.85 \%$ newly-formed bone after six months [27]. It is difficult to make a direct comparison between these two analyzes due to different defect architecture as wells as new bone formation, vascularization and graft particles degradation patterns. In addition, other study suggests that new bone formation increases over time in sites grafted with ABBMM [29]. More specifically, the new bone formation after sinus floor augmentation using ABBMM was about $36 \%$ at 6 months [30], and about $42 \%$ at 14 months [31]. Moreover, compared to 12 and 48 months of healing histomorphometric data at nine years showed a newly-formed bone increase of $18.45 \%$, and of $8 \%$, respectively [16]. 
Also the degradation time and ultimate fate of many commercially available bovine grafting materials at various grafted sites is also not fully understood. There are many variations among the tested models [13,32-34], cell types [11,34] and the histological preparation methods [9]. While it is generally accepted that graft particles undergo resorption by osteoclasts [15,34-36], it is documented that multinucleated cells are also present on the surface of the material [7-39]. Its hard to distinguishing between osteoclasts or macrophage polykaryons and if these cells are active osteoclasts, nonactive/impaired osteoclasts, giant cells or macrophages/monocytes undergoing fusion [40].

In order to better understand the degradation process, it is important to identify the type of cells surrounding the ABBMM particles. The histologic sections from the present study demonstrated multi-nucleated cells in close approximation and in contact with new bone while the osteoblastic lineage formed new bone onto the ABBMM surface (Figure 6). Such a histologic pattern has been previously defined as "functional coupling in the bone metabolic unit" [41]. It is suggested that the multinucleated giant cells observed in the present study could have the function of macrophages polykaryons. They probably "clean" the graft particles surface from the degradation products and therefore prepare the conditions for deposition of newly-formed bone [41].

In sites grafted with ABBMM after the first initial healing period (3-6 months), the osteoclastic activity in the microenvironment around the biomaterial particles could be inhibited by progressive increase of $\mathrm{Ca}^{2+}$ ions concentration [16]. It has been documented that acid secretion by osteoclasts causes mineral release from the substratum surface, which leads to an increase in $\mathrm{Ca}^{2+}$ ions in this compartment [16]. This, in turn, slows down the osteoclastic activity [42]. Ultrastructural analysis by backscattered electron imaging analysis showed a higher $\mathrm{Ca} / \mathrm{P}$ ratio in the residual the interface compared with new bone [43]. This suggests that there may be a gradual diffusion of $\mathrm{Ca}^{2+}$ ions from the biomaterial into the newly-forming bone at the interface as part of the biomaterial's resorption process. The presence of many translucent area at the interface between the biomaterial particles and newly formed bone and osteoid tissue found in the present study may represent the lytic process of the graft (Figure 5).

The degradation process of bovine-derived bone depends on the production process that can cause variations in physicochemical properties, hydrophilicity, and viscoelasticity $[44,45]$. More specifically, the high temperature sintering method leads to increased mineral crystalline size, which imparts a lower degradation rate if compared to the low temperature and chemical treatment methods.

The degradation process is influenced also by pores morphology, degree of porosity, pores' interconnections, and granule size distribution [46]. A decrease in pore connectivity could influence the possibility that a greater number of osteoblasts can penetrate the porous structure. In addition, also the degree of angiogenesis and the resulting flux of nutrient and of oxygen could be lower [47].

Another interesting data documented in the present study is related to the higher mean of osteocytes/area measured in the bone around the grafted particles compared to those found in the bone at a distance from the particles. The complex biologic function of osteocytes is still to be elucidated. It was suggested that osteocyte play a relevant role in the bone homeostasis and remodeling [48]. Osteocytes may produce signals to control osteoblast and bone lining cell functions, and thereby regulate bone modeling and help with new bone formation [49,50]. In vitro studies showed that osteocytes are negative regulator of osteoclast activity and may play a major role in triggering local bone remodeling [51]. In particular, it has been documented that osteocyte apoptosis triggers a bone remodeling response, while the neighboring non-apoptotic osteocytes are a major source of pro-osteoclastogenic signals. Moreover, both the apoptotic and osteoclast signaling osteocyte populations are localized in a spatially and temporally restricted pattern consistent with the targeted nature of remodeling response [52]. Lacking sufficient live osteocytes possibly leads to inefficiency in the remodeling activity. The higher number of osteocytes/area found in the present study in bone around the grafted particles, compared to bone at a distance from the graft, could be considered a "bone strategy" to overcome the absence of functional syncytium inside the biomaterial particles $[52,53]$. 
Most of the histological analysis after sinus augmentation report results at implant placement time during 6 to 9 months post grafting. Even though the present study is limited by the small sample size of three biopsies taken from one and the same patient, it still gives a general idea regarding the degradation process of ABBMM following sinus lift procedure after 24 months of healing. The histologic and histomorphometric analysis showed that a great amount of the residual grafting material was still present but it was still less than the newly-formed bone. More studies are required to understand the new bone formation patterns at different time points and in various grafted defects.

\section{Conclusions}

The present histologic and histomorphometric analysis was aimed to compare histomorphometric measures for newly-formed bone, marrow spaces, biomaterial particles remnants, and number of osteocytes embedded in both trabecular bone and bone tissue near the ABBMM. At two years healing time following sinus augmentation ABBMM underwent significant degradation. The tissue pattern appeared composed by residual ABBMM particles in close contact to the newly-formed bone and to osteoid tissue.

Author Contributions: R.G., L.T., and B.F.: substantial contributions to research design, drafting the paper, and the acquisition of data. D.P.: the analysis of data. All authors: the interpretation of data, revising the paper critically, and approval of the submitted and final versions.

Funding: The study was supported by BioHorizons, Birmingham, AL, USA, who provided the materials.

Conflicts of Interest: The authors reported no conflicts of interest related to this study.

\section{References}

1. Jensen, O.T.; Shulman, L.B.; Block, M.S.; Iacono, V.J. Report of the Sinus Consensus Conference of 1996. Int. J. Oral Maxillofac. Implants 1998, 13, 11-45. [PubMed]

2. Hallman, M.; Hedin, M.; Sennerby, L.; Lundgren, S. A prospective 1-year clinical and radiographic study of implants placed after maxillary sinus floor augmentation with bovine hydroxyapatite and autogenous bone. J. Oral Maxillofac. Surg. 2002, 60, 277-284. [CrossRef] [PubMed]

3. Misch, C.E.; Dietsh, F. Bone-grafting materials in implant dentistry. Implant Dent. 1993, 2, 158-167. [CrossRef] [PubMed]

4. Hallman, M.; Lederlund, A.; Linsskog, S.; Lundgren, S.; Sennerby, L. A clinical histologic study of bovine hydroxyapatite in combination with autogenous bone and fibrin glue for maxillary sinus floor augmentation. Results after 8 months of healing. Clin. Oral Implants Res. 2001, 12, 135-143. [CrossRef] [PubMed]

5. Block, J.E.; Poser, J. Does xenogeneic demineralized bone matrix have clinical utility as a bone graft substitute? Med. Hypotheses 1995, 45, 27-32. [CrossRef]

6. Jensen, S.S.; Aaboe, M.; Pinholt, E.M.; Hjørting-Hansen, E.; Melsen, F.; Ruyter, I.E. Tissue reaction and material characteristics of four bone substitutes. Int. J. Oral Maxillofac. Implants 1996, 11, 55-66. [PubMed]

7. Tadjoedin, E.S.; de Lange, G.L.; Bronckers, A.L.; Lyaruu, D.M.; Burger, E.H. Deproteinized cancellous bovine bone (Bio-Oss ${ }^{\circledR}$ ) as bone substitute for sinus floor elevation. A retrospective, histomorphometrical study of five cases. J. Clin. Periodontol. 2003, 30, 261-270. [CrossRef] [PubMed]

8. De Misquita, M.R.; Bentini, R.; Goncalves, F. The performance of bone tissue engineering scaffolds in in vivo animal models: A systematic review. J. Biomater. Appl. 2016, 31, 625-636. [CrossRef] [PubMed]

9. Hallman, M.; Thor, A. Bone substitutes and growth factors as an alternative/complement to autogenous bone for grafting in implant dentistry. Periodontology 2000, 47, 172-192. [CrossRef] [PubMed]

10. Pjetursson, B.E.; Tan, W.C.; Zwahlen, M.; Lang, N.P. A systematic review of the success of sinus floor elevation and survival of implants inserted in combination with sinus floor elevation. J. Clin. Periodontol. 2008, 35 (Suppl. 8), 216-240. [CrossRef] [PubMed]

11. Araújo, M.; Linder, E.; Wennström, J.; Lindhe, J. The influence of Bio-Oss Collagen on healing of an extraction socket: An experimental study in the dog. Int. J. Periodontics Restor. Dent. 2008, 28, 123-135. 
12. Rosenlicht, J.L.; Tarnow, D.P. Human histologic evidence of integration of functionally loaded implants placed simultaneously with sinus augmentation: A case report 2.5 years postplacement. J. Oral Implantol. 1999, 25, 7-10. [CrossRef]

13. Piattelli, M.; Favero, G.A.; Scarano, A.; Orsini, G.; Piattelli, A. Bone reactions to anorganic bovine bone $\left(\right.$ Bio-Oss $^{\circledR}$ ) used in sinus lifting procedure: A histologic long-term report of 20 cases in man. Int. J. Oral Maxillofac. Implants 1999, 14, 835-840. [PubMed]

14. Ewers, R.; Goriwoda, W.S.; Chopper, C.; Moser, D.; Spassova, E. Histologic findings at augmented bone areas supplied with two different bone substitute materials combined with sinus floor lifting. Report of one case. Clin. Oral Implants Res. 2004, 15, 96-100. [CrossRef] [PubMed]

15. Scarano, A.; Pecora, G.; Piattelli, M.; Piattelli, A. Osseointegration in a sinus augmented with bovine porous mineral: Histological results in an implant retrieved 4 years after insertion. A case report. J. Periodontol. 2004, 75, 1161-1166. [CrossRef] [PubMed]

16. Traini, T.; Valentini, P.; Iezzi, G.; Piattelli, A. A Histologic and Histomorphometric Evaluation of Anorganic Bovine Bone Retrieved 9 Years after a Sinus Augmentation Procedure. J. Periodontol. 2007, 78, 955-961. [CrossRef] [PubMed]

17. Zaffe, D.; Leghissa, G.C.; Pradelli, J.; Botticelli, A.R. Histological study on sinus lift grafting by Fisiograft and Bio-Oss. J. Mater. Sci. Mater. Med. 2005, 16, 789-793. [CrossRef] [PubMed]

18. Schlegel, A.K.; Donath, K. Bio-Oss-A resorbable bone substitute? J. Long-Term Eff. Med. Implants 1998, 8, 201-209. [PubMed]

19. Artzi, Z.; Nemcovsky, C.E.; Dayan, D. Bovine-HA spongiosa blocks and immediate implant placement in sinus augmentation procedures. Histopathological and histomorphometric observations on different histological stainings in 10 consecutive patients. Clin. Oral Implants Res. 2002, 13, 420-442. [CrossRef] [PubMed]

20. Galindo-Moreno, P.; Hernández-Cortés, P.; Mesa, F.; Carranza, N.; Juodzbalys, G.; Aguilar, M.; O’Valle, F. Slow resorption of anorganic bovine bone by osteoclasts in maxillary sinus augmentation. Clin. Implant Dent. Relat. Res. 2013, 15, 858-866. [CrossRef] [PubMed]

21. Corbella, S.; Taschieri, S.; Weinstein, R.; Del Fabbro, M. Histomorphometric outcomes after lateral sinus floor elevation procedure: A systematic review of the literature and meta-analysis. Clin. Oral Implants Res. 2016, 27, 1106-1122. [CrossRef] [PubMed]

22. Barone, A.; Aldini, N.N.; Fini, M.; Giardino, R.; Calvo Guirado, J.L.; Covani, U. Xenograft versus extraction alone for ridge preservation after tooth removal: A clinical and histomorphometric study. J. Periodontol. 2008, 79, 1370-1377. [CrossRef] [PubMed]

23. Barone, A.; Toti, P.; Quaranta, A.; Alfonsi, F.; Cucchi, A.; Negri, B.; Di Felice, R.; Marchionni, S.; Calvo-Guirado, J.L.; Covani, U.; et al. Clinical and Histological changes after ridge preservation with two xenografts: Preliminary results from a multicentre randomized controlled clinical trial. J. Clin. Periodontol. 2017, 44, 204-214. [CrossRef] [PubMed]

24. Jensen, S.S.; Broggini, N.; Hjørting-Hansen, E.; Schenk, R.; Buser, D. Bone healing and graft resorption of autograft, anorganic bovine bone and beta-tricalcium phosphate. A histologic and histomorphometric study in the mandibles of minipigs. Clin. Oral Implants Res. 2006, 17, 237-243. [CrossRef] [PubMed]

25. Artzi, Z.; Weinreb, M.; Givol, N.; Rohrer, M.D.; Nemcovsky, C.E.; Prasad, H.S.; Tal, H. Biomaterial resorption rate and healing site morphology of inorganic bovine bone and beta-tricalcium phosphate in the canine: A 24 month longitudinal histologic study and morphometric analysis. Int. J. Oral Maxillofac. Implants 2004, 19, 357-368. [PubMed]

26. Galindo-Moreno, P.; Moreno-Riestra, I.; Avila, G.; Fernández-Barbero, J.E.; Mesa, F.; Aguilar, M.; Wang, H.L.; $\mathrm{O}^{\prime}$ Valle, F. Histomorphometric comparison of maxillary pristine bone and composite bone graft biopsies obtained after sinus augmentation. Clin. Oral Implants Res. 2010, 21, 122-128. [CrossRef] [PubMed]

27. Guarnieri, R.; DeVilliers, P.; Grande, M.; Stefanelli, L.V.; Di Carlo, S.; Pompa, G. Histologic evaluation of bone healing of adjacent alveolar sockets grafted with bovine and porcine-derived bone: A comparative case report in humans. Regener. Biomater. 2017, 4, 125-128. [CrossRef]

28. Greenspan, D.C. Physical and Chemical Properties of Commercially Available Mineralized Bone Allograft. Available online: http:/ /www.zimmerbiomet.co.il/images/zimmer_minisite_2608\%201.pdf (accessed on 6 August 2018). 
29. Danesh-Sani, S.A.; Engebretson, S.P.; Janal, M.N. Histomorphometric results of different grafting materials and effect of healing time on bonematuration after sinus floor augmentation: A systematic review and meta-analysis. J. Periodont. Res. 2017, 52, 301-312. [CrossRef] [PubMed]

30. Felice, P.; Scarano, A.; Pistilli, R.; Checchi, L.; Piattelli, M.; Pellegrino, G.; Esposito, M. A comparison of two techniques to augment maxillary sinuses using the lateral window approach: Rigid synthetic resorbable barriers versus anorganic bovine bone. Five-month post-loading clinical and histological results of a pilot randomised controlled clinical trial. Eur. J. Oral Implantol. 2009, 2, 293-306. [PubMed]

31. Hallman, M.; Sennerby, L.; Lundgren, S. A clinical and histologic evaluation of implant integration in the posterior maxilla after sinus floor augmentation with au-togenous bone, bovine hydroxyapatite, or a 20:80 mixture. Int. J. Oral Maxillofac. Implants 2002, 17, 635-643. [PubMed]

32. McAllister, B.S.; Margolin, M.D.; Cogan, A.G.; Buck, D.; Hollinger, J.O.; Lynch, S.E. Eighteen-month radiographic and histologic evaluation of sinus grafting with anorganic bovine bone in the chimpanzee. Int. J. Oral Maxillofac. Implants 1999, 14, 361-368. [PubMed]

33. Carmagnola, D.; Berglundh, T.; Lindhe, J. The effect of a fibrin glue on the integration of Bio-Oss with bone tissue: A experimental study in labrador dogs. J. Clin. Periodontol. 2002, 29, 377-383. [CrossRef] [PubMed]

34. Perrotti, V.; Nicholls, B.M.; Horton, M.A.; Piattelli, A. Human osteoclast formation and activity on a xenogenous bone mineral. J. Biomed. Mater. Res. A 2009, 90, 238-246. [CrossRef] [PubMed]

35. Hammerle, C.H.F.; Chiantella, G.C.; Karring, T.; Lang, N.P. The effect of a deproteinized bovine bone mineral on bone regeneration around titanium dental implants. Clin. Oral Implants Res. 1998, 9, 151-162. [CrossRef] [PubMed]

36. Hürzeler, M.B.; Quiñones, C.R.; Kirsch, A.; Gloker, C.; Schüpbachs, P.; Strub, J.R.; Caffesse, R.G. Maxillary sinus augmentation using different grafting materials and dental implants in monkeys. Part I. Evaluation of anorganic bovine-derived bone matrix. Clin. Oral Implants Res. 1997, 8, 476-486. [CrossRef] [PubMed]

37. Araújo, M.G.; Liljenberg, B.; Lindhe, J. Dynamics of Bio-Oss Collagen incorporation in fresh extraction wounds: An experimental study in the dog. Clin. Oral Implants Res. 2010, 21, 55-64. [CrossRef] [PubMed]

38. Merkx, M.A.; Maltha, J.C.; Freihofer, H.P. Incorporation of composite bone implants in the facial skeleton. Clin. Oral Implants Res. 2000, 11, 422-429. [CrossRef] [PubMed]

39. Simion, M.; Fontana, F.; Rasperini, G.; Maiorana, C. Vertical ridge augmentation by expanded-polytetrafluoroethylene membrane and a combination of intraoral autogenous bone graft and deproteinized anorganic bovine bone (Bio Oss). Clin. Oral Implants Res. 2007, 18, 620-629. [CrossRef] [PubMed]

40. Kadoya, Y.; Al-Saffar, N.; Kobayashi, A.; Revell, P.A. The expression of osteoclast markers on foreign body giant cells. Bone 1994, 27, 85-96. [CrossRef]

41. Pogoda, P.; Priemel, M.; Rueger, J.M.; Amling, M. Bone remodeling: New aspects of a key process that controls skeletal maintenance and repair. Osteoporos. Int. 2005, 16, 518-524. [CrossRef] [PubMed]

42. Ramaswamy, Y.; Haynes, D.R.; Berger, G.; Gildenhaar, R.; Lucas, H.; Holding, C.; Zreiqat, H. Bioceramics composition modulate resorption of human osteoclasts. J. Mater. Sci. Mater. Med. 2005, 16, 1199-1205. [CrossRef] [PubMed]

43. Ramírez-Fernández, M.P.; Calvo-Guirado, J.L.; Delgado-Ruiz, R.A.; Maté-Sánchez del Val, J.E.; Negri, B.; Penarrocha Diago, M. Ultrastructural study by backscattered electron imaging and elemental microanalysis of biomaterial-to bone interface and mineral degradation of bovine xenografts in maxillary sinus floor elevation. Clin. Oral Implants Res. 2013, 24, 645-651. [CrossRef] [PubMed]

44. Trajkovski, B.; Jaunich, M.; Müller, W.D.; Beuer, F.; Zafiropoulos, G.G.; Houshmand, A. Hydrophilicity, Viscoelastic and Physicochemical Properties Variations in Dental Bone Grafting Substitutes. Materials 2018, 11, 215. [CrossRef] [PubMed]

45. Riachi, F.; Naaman, N.; Tabarani, C.; Aboelsaad, N.; Aboushelib, M.N.; Berberi, A.; Salameh, Z. Influence of material properties on rate of resorption of two bone graft materials after sinus liftusing radiographic assessment. Int. J. Dent. 2012, 2012. [CrossRef] [PubMed]

46. Lapczyna, H.; Galea, L.; Wüst, S.; Bohner, M.; Jerban, S.; Sweedy, A.; Doebelin, N.; Van Garderen, N.; Hofmann, S.; Baroud, G.; et al. Effect of grain size and microporosity on the in vivo behaviour of $\beta$ tricalcium phosphate scaffolds. Eur. Cells Mater. 2014, 28, 299-319. [CrossRef]

47. Yamada, Y.; Tamura, T.; Hariu, K.; Asano, Y.; Sato, S.; Ito, K. Angiogenesis in newly augmented bone observed in rabbit calvarium using a titanium cap. Clin. Oral Implants Res. 2008, 19, 1003-1009. [CrossRef] [PubMed] 
48. Cullinane, D.M. The role of osteocytes in bone regulation: Mineral homeostasis versus mechanoreception. J. Musculoskelet. Neuronal Interact. 2002, 2, 242-244. [PubMed]

49. Bonewald, L.F. The amazing osteocyte. J. Bone Miner. Res. 2011, 26, 229-238. [CrossRef] [PubMed]

50. Martin, R.B. Toward a unifying theory of bone remodeling. Bone 2000, 26, 1-6. [CrossRef]

51. Gu, G.; Mulari, M.; Peng, Z.; Hentunen, T.A.; Väänänen, H.K. Death of osteocytes turns off the inhibition of osteoclasts and triggers local bone resorption. Biochem. Biophys. Res. Commun. 2005, 335, 1095-1101. [CrossRef] [PubMed]

52. Kennedy, O.D.; Herman, B.C.; Laudier, D.M.; Majeska, R.J.; Sun, H.B.; Schaffler, M.B. Activation of resorption in fatigueloaded bone involves both apoptosis and active pro-osteoclastogenic signaling by distinct osteocyte populations. Bone 2012, 50, 1115-1122. [CrossRef] [PubMed]

53. Qiu, S.; Rao, D.S.; Fyrhie, D.P.; Palmitkar, S.; Parfitt, A.M. The morphological association between microcracks and osteocyte lacunae in human cortical bone. Bone 2005, 37, 10-12. [CrossRef] [PubMed]

(C) 2018 by the authors. Licensee MDPI, Basel, Switzerland. This article is an open access article distributed under the terms and conditions of the Creative Commons Attribution (CC BY) license (http://creativecommons.org/licenses/by/4.0/). 